\title{
Portfolio Management: Hedge or Sell during a Crisis?
}

\author{
Ulrich R. Deinwallner, PhD
}

PhD Management and Finance, Walden University, USA

DOI: $10.36348 /$ sjef.2020.v04i05.001

| Received: 20.04.2020 | Accepted: 29.04.2020 | Published: 04.05.2020

*Corresponding author: Dr. Ulrich R. Deinwallner

\section{Abstract}

During a global crisis, like COVID-19, investors are often uncertain how to decide for their portfolios: Should they hedge or even sell? The purpose of this quantitative, comparative study was to investigate how three different hedging models (HM) perform in comparison. The research question was: what HM with exchange traded funds is most profitable for U.S. stock portfolios? In this study, GARCH $(1,1)$ models, hedging coefficients, simple moving average (SMA), and ttests were computed. To sell a portfolio seemed the most profitable strategy during a crisis with $\left(\mathrm{r}_{\mathrm{SMA}(24)}=4.37 \%\right.$ per month), with $\$ 5,000$ initial investment during 2000-2019. However, if the investor is indecisive, then a hedge strategy could buy the investor time with $\left(\mathrm{r}_{\text {Hedged }}=1.87 \% \%\right.$ per month) during market uncertainties. The paper is relevant for investors and portfolio managers who have to decide hedge or sell a portfolio during a crisis, since an analysis of three different HMs in comparison is provided.

Keywords: Portfolio management, Hedging, Beta hedge, Minimum Risk hedge, GARCH model, Investment Strategy.

Copyright @ 2020: This is an open-access article distributed under the terms of the Creative Commons Attribution license which permits unrestricted use, distribution, and reproduction in any medium for non-commercial use (NonCommercial, or CC-BY-NC) provided the original author and source are credited.

\section{INTRODUCTION Hedging}

Much has been published to the issue of hedging in the scholarly literature since the early 1980 s and the introduction of stock index futures. Figlewski [1] introduced two main concepts to optimal hedging of portfolios, the minimum risk (variance) hedge, where a correlation coefficient was relevant for the computation between the spot and the future returns; and the Beta hedge, which depended on the computation of the covariance between the spot and the future returns. Both concepts seemed most effective, however, the minimum risk hedge provided higher returns in Figlewski's [1] study. Essentially, an insight was that only with a perfect correlation of one, between both the spot and the future returns, risk can be eliminated completely through a hedge for a portfolio [1]. Other relevant mathematical concepts to hedging were presented by Alexander [2], Allayannis, Ihrig and Weston [3], Arouri, Lahiani, and Nguyen [4], Benninga and Wiener [5], Bouleau and Lamberton [6], Branger and Mahayni [7], Černý, and Kallsen [8], Chang, McAleer, and Tansuchat, [9], Gennotte and Leland [10], Gleason, Kim, and Mathur [11], Hammoudeh, Yuan, McAleer, and Thompson [12], Harrison and Van Mieghem [13], Hobson and Klimmek [14], Mello, and Parsons [15], Schweizer [16], Schweizer [17], Windcliff, Forsyth, and Vetzal [18], which discussed all kinds of hedging variations for crude oil, Gold, exchange rate hedging, volatility transmission, residuals risk, market liquidity, dynamic hedging, and cointegration. However, it was Park and Switzer [19] who computed a "Generalized Autoregressive Conditional Heteroscedastic" (GARCH) Model to estimate the conditional variance for the computation of a hedging model (HM). While Basher and Sadorsky [20] presented a GARCH and a "Dynamic Conditional Correlation" (DCC) model to estimate the conditional correlation coefficient to compute for example an estimated minimum risk HM. Essentially, many different forms of hedging have been elaborated in the scholarly literature and two relevant models to mention are the minimum risk and the Beta HM.

\section{GARCH}

In the scholarly finance literature, the GARCH model has also been well discussed. Engle [21] and Bollerslev [22] mentioned that a GARCH model allows estimating a time-dependent conditional variance in the unconditional distribution of price changes, while relaxing the assumption of independent successive price changes. With the GARCH model it is possible to find weak dependence of interactions at higher dispositions. The GARCH model was proven as successful for explaining the price movements of stock returns [22, 23]. While, Baillie and Meyers [24], Gagnon and Lypny [25], Kroner and Sultan [26], Myers [27] made similar 
contributions to the issue of GARCH model and in regard of estimating the metrics for a HM through a GARCH model. Based on these researchers' findings, a GARCH model can support an investor determining the hedge ratios. While the results of a $\mathrm{HM}$ and obtained from the GARCH model are expected to provide a lower risk profile when hedging a portfolio.

The current situation is that many studies have tested the issue of hedging on the basis of futures. However, retail investors might not have access to a future or option accounts and have to hedge their portfolios either with exchange traded funds (ETFs) or in Germany for example with Knock Out (KO) certificates. Therefore, the general problem is that more in the literature can be investigated to the issue of testing hedging strategies with ETFs. The specific problem was that since there are more than one ways to hedge a portfolio, retail investors need to decide what hedging strategy to choose and what HM brings the best performance. Therefore, a test of different HMs is required based on a U.S. stock portfolio and based on a correlated index Short ETF. The findings can provide insights for investors and portfolio managers to better understand what hedging strategy to choose, what returns to expect, when hedging their portfolios with ETFs. This research can be significant to contribute to the issue of ETF hedging in the scholarly literature, where more information to this issue is provided at the end of this paper.

Therefore, the purpose of this quantitative, comparative study is to investigate three different HM and to compare an unhedged portfolio performance (independent variable) to a hedged portfolio performance (dependent variable) of a two U.S. stock portfolio (PO) to determine the optimal hedging strategy and to answer the research question (RQ).

\section{Research Question}

This study is guided by one RQ: What HM model with ETFs is most profitable for U.S. stock portfolios?

To answer the research question two Hypotheses $(H)$ are relevant to investigate:

$H_{0} 1$ : if three different HMs are compared, HM1 (based on correlation), HM2 (based on covariance), HM3 (based on covariance and estimated variance), then HM3 exhibits the optimal risk values but does not outperform the other models.

$H_{1} 1$ : if three different HMs are compared, HM1-3, then HM3 exhibits the optimal risk values and outperforms the other models.

$H_{0}$ 2: if a PO buy and hold, PO SMA (24) hedged, and PO SMA (24) buy and sell trading strategy are compared, then the PO hedged strategy does not outperform the other strategies.

$H_{1}$ 2: if a PO buy and hold, PO SMA (24) hedged, and PO SMA (24) buy and sell trading strategy are compared, then the PO hedged strategy outperforms the other strategies.

\section{Summary}

In this paper, I investigate the question if an investor should hedge or sell a stock portfolio during a crisis. First, I present a descriptive analysis of the PO and the ETF. Then, the GARCH $(1,1)$ model coefficients are computed to estimate the conditional variance for HM3. I compare three HMs by investigating an arbitrage performance. For the arbitrage performance, I buy a PO and buy an ETF Short at the same time, for an investment amount of initial $\$ 5,000$. The returns in Table 3 show that the GARCH estimated HM3 exhibits the highest returns $\left(r_{P O}{ }_{\text {HM } 3}=0.49 \%\right.$ per month $)$, however, the HM1 covers the losses the best during declining markets. This observation is caused through the different computation types of the HMs and caused through the different recommended investment amount for the ETF for the hedge. Finally, I answer the RQ and I answer how to decide, if to hedge or to sell a portfolio during a crisis. I compare a buy and hold, SMA (24) hedged, and SMA (24) buy and sell strategy with an initial investment amount of $\$ 5,000$. To sell seemed the most profitable option $\left(r_{S M A(24)}=4.37 \%\right.$ per month), however, if the investor is indecisive, then a hedging strategy could buy the investor time with $\left(r_{\text {Hedged }}=1.87 \%\right.$ per month). For the analysis, daily and monthly Dow Jones Industrial Average (DJIA) stock market data was considered for the time period 2000-2019. The paper can contribute to the literature of hedging with ETFs. The paper is relevant for investors and portfolio managers who have to decide to hedge or to sell their stock portfolio during a crisis.

\section{DATA AND METHODOLOGY}

For the analysis, I use dividend adjusted daily closing prices, daily and monthly data, from the DJIA Index and two stocks of Walt Disney (DIS) and Goldman Sachs (GS) for the time period of January 01, 2000 until December 31, 2019 (20 years). I collect the DJIA and stocks data from the internet source Yahoo! Finance [33]. The computation of the GARCH model will require statistic software. For the computation I use $\mathrm{R}$ studio and the packages RUGARCH [28].

I make the following limitations for the results of this study in regard of U.S. security portfolios and for the data of the DJIA. Size effects might not be present in the selected data since the DJIA only represents large cap stocks. Other hedging strategies have been mentioned in the literature besides the HM1, HM2, and HM3, however, the scope in this study is only based on these three HM's. The findings can be relevant for investors and portfolio managers who are interested in the differences of the three HMs and the hedging performance with ETFs. 


\section{Methodology}

In the methodology section, I define the equations that are considered in this paper. I consider the following equation (a) the hedging coefficients
HM1-3, (b) the GARCH model, (c) the computation of the ETF price, (d) the transaction costs, (e) a simple moving average, (f) a $t$-test:

HM1:

$$
\begin{aligned}
& \beta^{*}=\frac{\rho_{p i} * \sigma_{p} * \sigma_{i}}{\sigma_{i}^{2}}=\rho_{p i} \frac{\sigma_{p}}{\sigma_{i}} \\
& h=\beta^{*} \frac{\sigma_{p}^{2}}{\sigma_{i}^{2}}
\end{aligned}
$$

HM2:

$$
h^{*}=\left(\frac{\sigma_{i p}}{\sigma_{p}^{2}}\right)\left(\frac{\sigma_{p}^{2}}{\sigma_{i}^{2}}\right)=\beta_{i} \frac{\sigma_{p}^{2}}{\sigma_{i}^{2}}
$$

HM3:

$$
\hat{h}^{*}=\left(\frac{\sigma_{p i}}{\hat{\sigma}_{p}^{2}}\right)\left(\frac{\hat{\sigma}_{p}^{2}}{\hat{\sigma}_{i}^{2}}\right)=\hat{\beta}_{i} \frac{\hat{\sigma}_{p}^{2}}{\hat{\sigma}_{i}^{2}}
$$

The HMs are oriented at Figlewski's [1] and Park and Switzer's [19] findings. To obtain the investment amount $I A$, to invest in the ETF, the $\mathrm{PO}$ value $V_{p}$ (i.e. $\$ 5,000$ ) is required:

$$
I A=-V_{p} \beta^{*} \frac{\sigma_{p}^{2}}{\sigma_{i}^{2}}
$$

Where $\beta=$ Beta, $\sigma_{i p}=$ the covariance between $p$ the PO returns and $i$ the ETF returns, $\sigma^{2}=$ the variance, $\sigma$ $=$ the standard deviation (STD), and $\rho_{p i}=$ the correlation coefficient between $p$ and $i$.

GARCH:

$$
\sigma_{t}^{2}=\left(\omega+\sum_{j=1}^{m} \zeta_{j} v_{j t}\right)+\sum_{j=1}^{q} \alpha_{j} \varepsilon_{t-j}^{2}+\sum_{j=1}^{p} \beta_{j} \sigma_{t-j}^{2}
$$

The GARCH model is according to Bollerslev [22], where " $\sigma_{t}^{2}$ denoting the conditional variance, $\omega$ is the intercept and $\varepsilon_{t}^{2}$ are the residual from a mean filtration process [...]. The GARCH order is defined by (q, p) (ARCH, GARCH), with possibly m external regressors $v_{j}$ which are passed pre-lagged" [28].

Former R GARCH versions computed a $\operatorname{ARMA}(1,1)-\operatorname{GARCH}(1,1)$ model:

$$
\begin{aligned}
& r_{t}=\mu+\varphi_{1} r_{t-1}+a_{t}+\theta_{1} a_{t-1} \\
& a_{t}=\sigma_{t} \varepsilon_{t} \\
& \sigma_{t}^{2}=\omega+\alpha_{1} a_{t-1}^{2}+\beta_{1} \sigma_{t-1}^{2} \\
& \varepsilon_{t} \sim i . i . d(0,1, \gamma)
\end{aligned}
$$

Where the outputs of the GARCH model are for the software R Studio $\mu=$ mu, $\varphi_{1}=\operatorname{ar} 1, \theta_{1}=$ ma1, $\omega=$ omega, $\alpha_{1}=$ alpha1, $\beta_{1}=$ beta1, $\gamma=$ the degrees of freedom, and $\sigma_{t-1}^{2}=$ yesterday's variance.

ETF Short:

$$
p_{S i}=V-\left(\left(L N\left(p_{i t}\right)-L N\left(p_{i t-1}\right)\right) * 100\right)
$$

Where $p_{S i}=$ the price of the ETF Short of asset $i$ at time $t$, and $p_{i}=$ the price of the underlying asset (here DJIA), $V$ is the value. The Equation 5 displays how the price of an ETF Short is computed. For example, if the initial values is $V=\$ 100$, the DJIA 
is at 23,000 points and increases by 100 points, then $\mathrm{LN}(23100)-\mathrm{LN}(23000) * 100=+0.4338 \%$. This means for the ETF Short $\$ 100-0.4338=\$ 99.5662$. Through this form of computation a path dependency occurs, which means that if the index increases and declines again, the ETF price might not be at breakeven level again. For example, if the DJIA increases to
23,100 points and reaches then the initial 23,000 points again, then the ETF price could exhibits a slight loss. This is relevant to know, since deviation could occur in regard of the subsequent tested results [29]. For the ETF Short and for the computation of the ETF Short returns, I will consider the DIJIA data.

\section{Transaction costs}

$$
o=V *(2 * c)
$$

Where, $V=$ portfolio value or the invested amount, $c=$ sales commission of $1 \%$ per trade via Broker (i.e. Tradegate or others) for stocks and ETFs, $o=$ is the total costs implied for one trade (Buy and Sell action).

\section{Simple Moving Average (SMA)}

$$
S M A=\frac{P_{p}+P_{p-1}+\ldots+P_{p-(n-1)}}{n}
$$

Where, $P_{p}=$ the price of the asset $p$; and $n=$ the number of days considered for the closing.

STD of a two stock portfolio:

$$
\sigma_{p}=\left(w_{A}^{2} \sigma_{A}^{2}+w_{B}^{2} \sigma_{B}^{2}+2 w_{A} w_{B} \sigma_{A} \sigma_{B} \rho_{A B}\right)^{1 / 2}
$$

Where, $\sigma=$ the STD of a $p$ two asset portfolio or of asset $\mathrm{A}$ and $\mathrm{B}, \sigma^{2}=$ the variance of asset $\mathrm{A}$ and $\mathrm{B}, w=$ the weight of asset $\mathrm{A}$ and $\mathrm{B}$ of $p, \rho_{A B}=$ the correlation coefficient between asset $\mathrm{A}$ and $\mathrm{B}$.

\section{Mean difference significance test (t-test)}

$$
t=\frac{X_{1}-X_{2}}{\sqrt{\frac{\sigma_{1}}{n_{1}}+\frac{\sigma_{2}}{n_{2}}}}
$$

Where, $\mathrm{X}=$ the average return, $\sigma=$ the STD, and $n=$ the number of cases [30].

\section{RESEARCH DESIGN}

I will test the following steps according to the research design: (a) I provide a descriptive analysis of the PO and the ETF Short. (b) Then, daily volatility values will be computed for a chart, to visualize the PO volatility during the given time period 2000-2019. (c) I will compute the GARCH $(1,1)$ coefficient from the PO returns and the ETF Short returns to estimate conditional variance for HM3 from daily data. (d) Next, a comparison is provided between the HMs1-3 of an arbitrage performance with daily data and with an initial investment amount of $\$ 5,000$. Arbitrage performance means that I will buy the PO and buy an ETF Short simultaneously over the time period 2000-2019. (e) Finally, a test will be conducted between a PO buy and hold strategy, PO SMA (24) hedging strategy, and PO SMA (24) buy and sell trading strategy with monthly data, with an initial investment amount of $\$ 5,000$, and over the time period 2000-2019.

\section{Threats to External Validity, Internal Validity, and Construct Validity}

Because private investors tend to lose capital in the financial markets, this study is for educational reasons, does not represent investment advice, and investors should conduct their own research before investing their capital [31]. Threats to external validity are that the results for ETF Short returns might not apply for future or option results if for example a comparison is conducted with other markets or assets. Further it is to consider that stock market tend to go up on average over the long-run and that hedging during declining markets can be seen as an exception rather than a rule [1]. Threats to internal validity are that the computations could be not precise. For example the transaction costs can be different according to which broker or bank was chosen. Also, for the computation of the GARCH model different (R Studio versions) assumptions of the settings can lead to deviating results in case of a comparison. As mentioned, I assume a path dependency effect for the ETF returns. This could lead to deviations for the results of the hedged PO returns and for the ETF returns. These aspects can lead to deviations and validity threats in regard of the subsequent tested results.

\section{EMPIRICAL FINDINGS \\ Analysis and Discussion of $\mathrm{H1}$}

For the analysis of $H 1$, I present a descriptive analysis with monthly average returns in Table 1 . The ETF (here and after) started in 2000 with \$100, was 
inverse (Short) connected to the DJIA returns, and the PO weights $(w)$ of stocks $(\mathrm{A}=\mathrm{DIS} ; \mathrm{B}=\mathrm{GS})$ were $\left(w_{A}=\right.$

$$
\left.50 \%, w_{B}=50 \%\right)
$$

Table-1

\begin{tabular}{|l|c|c|c|c|c|}
\hline \multicolumn{3}{|c|}{ Descriptive analysis of assets during 2000-2019 } & KS & $\bar{r}$ & STD \\
\hline & Skewness & Kurtosis & 0.080 & 0.97 & 8.23 \\
\hline PO & 0.400 & 10.793 & 0.135 & -0.67 & 8.89 \\
\hline
\end{tabular}

Note. KS is a Kolmogorov-Smirnov test for normality (all values are significant), $\bar{r}$ is the mean return, all returns are monthly in (\%). In the table, a descriptive analysis of the distribution of the data was conducted.

In Figure 1, I provide a plot of the PO volatility. In the plot, the effects of the financial (or Bank) crisis in 2008 can be seen clearly with a large volatility spike.

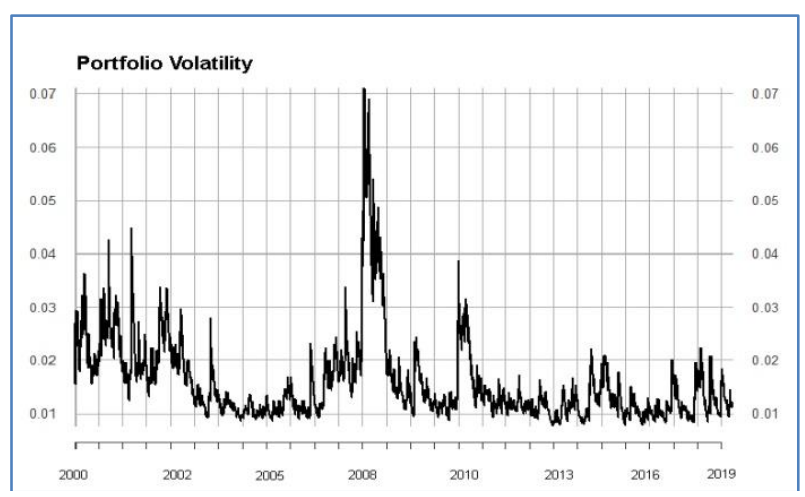

Fig-1: Displaying the daily volatility of the PO during 2000-2019

Next, I computed a GARCH model and display the coefficient in Table 2. The data were the daily returns of the PO and the ETF. The correlation coefficient, between the PO and the ETF returns, displayed a low overall negative correlation with $\left(\rho_{\text {PO\&ETF }}=-0.54\right)$, however, this value considered for a time period of 20 years, from 2000-2019. It is to mention that a low correlation between a portfolio and a hedging instrument would lead to larger deviations for a hedge. In other words, only a high correlation of near 1 would equal to a perfect hedge.

Table-2

\begin{tabular}{|c|c|c|}
\hline \multicolumn{3}{|c|}{ Estimates of the GARCH model } \\
\hline Coefficient & $\mathrm{PO}$ & ETF \\
\hline \multirow[t]{2}{*}{$\omega$} & 0 & 0 \\
\hline & $(2.78)$ & $(0.929)$ \\
\hline \multirow[t]{2}{*}{$\alpha$} & 0.077 & 0.09 \\
\hline & $(8.510)$ & $(4.829)$ \\
\hline \multirow[t]{2}{*}{$\beta$} & 0.912 & 0.907 \\
\hline & $(89.448)$ & $(50.423)$ \\
\hline \multirow[t]{2}{*}{$\mu$} & 0.001 & 0 \\
\hline & (4.176) & $(4.383)$ \\
\hline \multirow[t]{2}{*}{$\varphi$} & 0.78 & 0.022 \\
\hline & (5.274) & $(0.083)$ \\
\hline \multirow[t]{2}{*}{$\theta$} & -0.8 & -0.067 \\
\hline & $(5.646)$ & $(0.253)$ \\
\hline$\rho_{\text {PO\&ETF }}$ & -0.54 & \\
\hline
\end{tabular}

For the analysis of Table 3, I considered daily data for the PO and the ETF returns. I computed the POs returns with an initial investment of $\$ 5,000$ plus the hedging amount invested in an ETF, which I obtained from Equation 1-3. For Table 3, I investigated the arbitrage performance of the PO and ETF, which means buying a PO and simultaneously buying an ETF Short. I obtained the overall returns for the tested time period 2000-2019, which equaled to 20 years. I subtracted the initial hedging amount from the PO value, divided $\left(\left(\mathrm{PO}_{\mathrm{n}} / \mathrm{PO}_{1}-1\right) * 100\right)$ where $(n=5,030$ daily returns), and extrapolated the daily returns to monthly values.

In Table 3, I present a comparison between the three different HMs according to Equation 1-3. The 
metrics showed that the estimated HM3 return seemed to be heuristically slightly more profitable for the PO with $\left(r_{P O \_H M 3}=0.49 \%\right.$ per month $)$ compared to the other $\mathrm{HM}$ values. However, this was only the case because the hedging amount was less for the estimated HM3 (Equation 3), compared to the hedging amount of the HM1. Since the market moved generally upwards, the losses through the hedges were smaller for the estimated HM3 which led to a higher return. In other words, the coverage against losses through a hedge might be more efficient, in declining market phases, for a HM1 strategy. Therefore, I will next test a PO buy and hold strategy and a SMA (24) PO hedging strategy for the HM1 on a monthly data basis. In regard of the hypothesis $\mathrm{H} 1$, I can find that $\mathrm{H} 1$ was not significant at a $1 \%$ alpha level.

Table-3

\begin{tabular}{|l|c|c|c|c|c|}
\hline \multicolumn{7}{|c|}{ Portfolio hedged by DJIA Short ETF over 2000-2019 } \\
\hline & \multicolumn{2}{|c|}{ Unhedged } & \multicolumn{3}{c|}{ HM1 } \\
\hline & $r$ & $\sigma$ & $h$ & $r$ & $\sigma$ \\
\hline Portfolio & 0.97 & 8.23 & 0.56 & 0.47 & 9.88 \\
\hline & & & $h^{*}$ & \multicolumn{2}{c|}{ HM2 } \\
\hline Portfolio & & & 0.53 & 0.47 & 9.88 \\
\hline & & & $\hat{h}^{*}$ & \multicolumn{2}{|c|}{ HM3 } \\
\hline Portfolio & & & 0.39 & 0.49 & 10.05 \\
\hline DJIA Short ETF & & & & \multicolumn{3}{l|}{} \\
\hline $\begin{array}{l}\text { Note. All values are means in (\%) and monthly extrapolated (except hedge coefficients). } \\
\text { Hedging coefficient are according to Equation 1, 2, and 4. }\end{array}$
\end{tabular}

\section{Analysis and Discussion of $\mathrm{H2}$}

For the analysis of $H 2$, I tested a PO buy and hold strategy (unhedged) and a SMA (24) PO HM1 hedging strategy (hedged) and a SMA (24) buy and sell strategy, with monthly data. Where, Glabadanidis [32] mentioned that for SMA trading strategy with monthly data, 24 months are most profitable to consider. First, I determined the buy and sell signals obtained from the DJIA and a SMA (24) trading strategy. This means, if the DJIA price crosses the SMA (24) from below to above, then a buy signal occurs vice versa. Since the formation period of the SMA took 24 months, I obtained ( $n=217$ months) of PO and ETF returns during 2000-2019.

I tested the unhedged strategy by investing $\$ 5,000$ in the PO, which was held from 12.2001 until 12.2019. Then, for the hedged strategy, the PO was hedged according to the SMA (24) sell signals with the HM1. To compute the HM1, I considered a 6 month formation period to compute the correlation and the variances, while adjusting the PO value over the given time period. Essentially, for the SMA (24) strategy, I sold the portfolio if a sell signal occurred and reinvested the hedging gains in the last portfolio value if a buy signal occurred.

I can draw the following conclusions from the data in Table 4. Hedging a portfolio seemed heuristically more profitable than not hedging a portfolio, however, there was no significant difference with $t$-test with $t(216)=0.1435, p=.4443$ caused through a high standard deviation. The effect of low correlation between the PO and the ETF returns could have also impacted here the results. Clearly, the investors should sell a portfolio, if there is an indication of declining or distressed markets, and the investor should rather hold cash or should invest in a profitable alternative to increase the performance. In regard of the hypothesis $H 2$, I can find that $\mathrm{H} 2$ was not significant at a $1 \%$ alpha level.

Table-4

\begin{tabular}{|c|c|c|c|c|}
\hline \multicolumn{5}{|c|}{ Unhedged versus hedged Portfolio strategy during 2000-2019 } \\
\hline Portfolio & Trades & $r_{c}$ & $\sigma$ & $r_{c} / \sigma$ \\
\hline Unhedged & 1 & 1.49 & 7.20 & 0.21 \\
\hline Hedged & 9 & 1.87 & 7.64 & 0.24 \\
\hline $\operatorname{SMA}(24)$ & 9 & 4.37 & 5.94 & 0.74 \\
\hline \multicolumn{5}{|c|}{$\begin{array}{l}\text { Note. In total } n=217 \text { months occurred during } 2000-2019 \text { (minus } 24 \text { months formation period } \\
\text { for the SMA (24)). } c \text { are the costs of }-2 \% \text { per trade (buy and sell; see Equation } 6) \text {. The initial } \\
\text { PO investment amount was } \$ 5,000 \text {. The monthly returns are in }(\%) \text {, while } r_{c} \text { are cost-adjusted } \\
\text { the returns. In the table an "unhedged" PO buy and hold strategy is compared to a "hedged" } \\
\text { PO SMA (24) HM1 strategy ( } 6 \text { months formation period / profits of hedge reinvested) and a } \\
\text { PO "SMA (24)" buy and sell strategy. }\end{array}$} \\
\hline
\end{tabular}




\section{CONCLUSION}

In this study, I tested three HMs 1-3 (see methodology section). The main RQ was: what HM with ETFs is most profitable for U.S. stock portfolios? The HM1 had the lowest returns for an arbitrage performance during 2000-2019. However, the computed hedge amount was the largest for the HM1 and seemed to cover the losses of the PO the best during declining markets. This finding seemed to be congruent with Figlewski [1] and corroborate his results. From a test between an unhedged, hedged and SMA (24) buy and sell PO strategy, the following can be mentioned. Hedging a portfolio is more profitable, than not hedging a portfolio (but not significant) if the hedging profits are reinvested in the portfolio. Selling in case of declining markets (holding cash or invest in alternatives) is clearly more profitable, than hedging an account. It is to mention that hedging can buy the investor time to make a decision and to assess the dimension of a crisis. Essentially, the investor could hedge during uncertainty and sell if markets come under distress. This finding can be relevant for investors and portfolio managers who stand ahead of stock market crises (i.e. COVID-19) and need to decide if to hedge or to sell their assets. More research could be investigated in regard of estimated HMs versus the degree of complexity for their application.

\section{REFERENCES}

1. Figlewski, S. (1984). Hedging performance and basis risk in stock index futures. The Journal of Finance, 39(3), $657-$ 669.https://doi.org/10.1111/j.15406261.1984.tb03654.x

2. Alexander, C. (1999). Optimal hedging using cointegration. Philosophical Transactions of the Royal Society of London. Series A: Mathematical, Physical and Engineering Sciences, 357(1758), 2039-2058. https://doi.org/10.1098/rsta.1999.0416

3. Allayannis, G., Ihrig, J., \& Weston, J. P. (2001). Exchange-rate hedging: Financial versus operational strategies. American Economic Review, 91(2), 391-395. https://pubs.aeaweb.org/doi/pdf/10.1257/aer.91.2.3 91

4. Arouri, M. E. H., Lahiani, A., \& Nguyen, D. K. (2015). World gold prices and stock returns in China: insights for hedging and diversification strategies. Economic Modelling, 44, 273-282. https://doi.org/10.1016/j.econmod.2014.10.030

5. Benninga, S., \& Wiener, Z. (1998). Dynamic hedging strategies. Mathematica in Education and Research, $7, \quad 12-16$. http://simonbenninga.com/wiener/MiER71.pdf

6. Bouleau, N., \&Lamberton, D. (1989). Residual risks and hedging strategies in Markovian markets. Stochastic Processes and their Applications, 33(1), 131-150. https://doi.org/10.1016/0304-
7. Branger, N., \&Mahayni, A. (2006). Tractable hedging: An implementation of robust hedging strategies. Journal of Economic Dynamics and Control, 30(11), 1937-1962. https://doi.org/10.1016/j.jedc.2005.06.014

8. Černý, A., \&Kallsen, J. (2007). On the structure of general mean-variance hedging strategies. The Annals of probability, 35(4), 1479. 1531.https://doi.org/10.1214/009117906000000872

9. Chang, C. L., McAleer, M., \&Tansuchat, R. (2011). Crude oil hedging strategies using dynamic multivariate GARCH. Energy Economics, 33(5), 912-923.

https://doi.org/10.1016/j.eneco.2011.01.009

10. Gennotte, G., \& Leland, H. (1990). Market liquidity, hedging, and crashes. The American Economic Review, 9991021.https://www.researchgate.net/profile/Hayne_ Leland/publication/4745533_Market_Liquidity_He dging_and_Crashes/links/5457bb0b0cf26d5090ab5 04b.pdf

11. Gleason, K., Kim, Y. S., \& Mathur, I. (2005). The operational and financial hedging strategies of US high technology firms. Documento de trabajo, Florida Atlantic University, Boca Raton, FL. https://www.ivey.uwo.ca/faculty/ssapp/teaching/em ba/techhedge.pdf

12. Hammoudeh, S. M., Yuan, Y., McAleer, M., \& Thompson, M. A. (2010). Precious metalsexchange rate volatility transmissions and hedging strategies. International Review of Economics \& Finance, 19(4), 633-647. https://doi.org/10.1016/j.iref.2010.02.003

13. Harrison, J. M., \& Van Mieghem, J. A. (1999). Multi-resource investment strategies: Operational hedging under demand uncertainty. European Journal of Operational Research, 113(1), 17-29. https://doi.org/10.1016/S0377-2217(97)00425-6

14. Hobson, D., \&Klimmek, M. (2012). Modelindependent hedging strategies for variance swaps. Finance and Stochastics, 16(4), 611649.https://arxiv.org/pdf/1104.4010.pdf

15. Mello, A. S., \& Parsons, J. E. (2000). Hedging and liquidity. The Review of Financial Studies, 13(1), 127-153.https://doi.org/10.1093/rfs/13.1.127

16. Schweizer, M. (1991). Option hedging for semimartingales. Stochastic processes and their Applications, 37(2), 339-363. https://doi.org/10.1016/0304-4149(91)90053-F

17. Schweizer, M. (1994). Risk- minimizing hedging strategies under restricted information. Mathematical Finance, 4(4), 327342.https://doi.org/10.1111/j.14679965.1994.tb00062.x

18. Windcliff, H., Forsyth, P. A., \&Vetzal, K. R. (2006). Pricing methods and hedging strategies for volatility derivatives. Journal of Banking \& Finance, 30(2), 409-431 https://doi.org/10.1016/j.jbankfin.2005.04.025 4149(89)90071-9 
19. Park, T. H., \& Switzer, L. N. (1995a). Timevarying distributions and the optimal hedge ratios for stock index futures. Applied Financial Economics, 5(3), 131-137. https://doi.org/10.1080/758523000a

20. Basher, S. A., \& Sadorsky, P. (2016). Hedging emerging market stock prices with oil, gold, VIX, and bonds: A comparison between DCC, ADCC and GO-GARCH. Energy Economics, 54, 235-247. https://doi.org/10.1016/j.eneco.2015.11.022

21. Engle, R. F. (1982). Autoregressive conditional heteroscedasticity with estimates of the variance of United Kingdom inflation, Econometrica, 50, 9871007.https://doi.org/10.2307/1912773

22. Bollerslev, T. (1986). Generalized autoregressive conditional heteroscedasticity, Journal of Econometrics. 31, 30727.http://www.u.arizona.edu/ rlo/readings/278762. pdf

23. French. K., Schwert, W., \& Stambaugh, R. (1987). Expected stock returns and volatility. Journal of Financial Economics, 19, 137-55. https://doi.org/10.1016/0304-405X(87)90026-2

24. Baillie, R. T., \& Myers, R. J. (1991). Bivariate GARCH estimation of the optimal commodity futures hedge, Journal of Apptied Econometrics, 6, 109-24.https://doi.org/10.1002/jae.3950060202

25. Gagnon, L., \& Lypny, G. (1997). The benefits of dynamically hedging the Toronto 35 stock index. Canadian Journal of Administrative Sciences, 14(1), 69-78. https://doi.org/10.1111/j.19364490.1997.tb00119.x

26. Kroner, K. F. and Sultan, J. (1993) Time varying distribution and dynamic hedging with foreign currency futures. Journal of Financial and Quantitative Analysis, 28, 53551.https://doi.org/10.2307/2331164

27. Myers, R. J. (1991) Estimating time varying optimal hedge ratios on future markets. Journal of Futures Markets, II, 3953.https://doi.org/10.1002/fut.3990110105

28. Ghalanos A (2020). rugarch: Univariate GARCH models.. $\mathrm{R}$ package version 1.4-2. https://cran.rproject.org/

29. ExtraETF. (2020). So funktionieren short ETFs [This is how short ETFs function]. https://de.extraetf/wissen/so-funktionieren-shortetfs

30. Chang, Y., Metghalchi, M., \& Chan, C. (2006). Technical trading strategies and cross-national information linkage: The case of Taiwan stock market. Applied Financial Economics, 16(10), 731-743. https://doi.org/10.1080/09603100500426374

31. Abbey, B. S., \& Doukas, J., A. (2012). Is technical analysis profitable for individual currency traders? Journal of Portfolio Management, 39(1), 142-150. https://doi.org/10.3905/jpm.2012.39.1.142

32. Glabadanidis, P. (2015). Market timing with moving averages. International Review of Finance, 15(3), 387-425. https://doi.org/10.1111/irfi.12052

33. Ren, L., \& Ren, P. (2018). Applying a combined max-min simple moving average trading strategy to market indexes. Economics, Management, \& Financial Markets, 13(2), 11-23. https://www.ceeol.com/search/article detail $? \mathrm{id}=676861$. 